\title{
Role of contrast-enhanced ultrasound to define prognosis and predict response to biotherapy in pancreatic neuroendocrine tumors
}

\author{
M. Del Prete ${ }^{1}$ A. Di Sarno ${ }^{2}$ R. Modica ${ }^{1} \cdot$ F. Lassandro $^{3} \cdot$ A. Giorgio $^{4} \cdot$ A. Bianco $^{2} \cdot$ M. Muto $^{4} \cdot$ M. Gasperi $^{5}$.

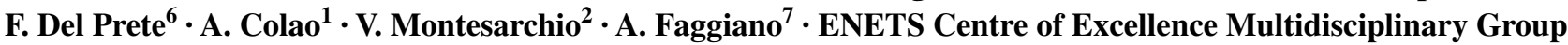 \\ for Neuroendocrine Tumors in Naples (Italy)
}

Received: 22 May 2017 / Accepted: 23 June 2017 / Published online: 30 June 2017

(C) Italian Society of Endocrinology (SIE) 2017

\begin{abstract}
Purpose The incidence of neuroendocrine tumors (NETs) is progressively increasing. Most cases arise from the digestive system, where ileum, rectum and pancreas represent the commonest site of origin. Liver metastases are frequently detected at diagnosis or during the follow-up. Contrast-enhanced ultrasound (CEUS) is used in patients with pancreatic NETs (P-NETs) and liver metastases from P-NET but its role has not been standardized. The aim of this retrospective study was to investigate CEUS in patients with P-NETs and liver metastases from P-NET both as prognostic factor and predictor of response to therapy with somatostatin analogues (SSAs).

Methods CEUS was performed at the diagnosis of NET and 3, 6 and 12 months after the beginning of SSAs. CEUS
\end{abstract}

M. Del Prete, A. Di Sarno equally contributed to the paper.

M. Del Prete

michidelpre@gmail.com

1 Department of Clinical Medicine and Surgery, Federico II University, Naples, Italy

2 UOC of Oncology, A.O. dei Colli, Monaldi Unit, Naples, Italy

3 UOC of Radiology, A.O. dei Colli, Monaldi Unit, Naples, Italy

4 Interventional Unit Ultrasound, A.O. dei Colli, D. Cotugno Unit, Naples, Italy

5 Department of Medicine and Health Sciences, Section of Endocrinology, University of Molise, Campobasso, Italy

6 Centre for Economic and International Studies, University of Rome "Tor Vergata", Rome, Italy

7 Thyroid and Parathyroid Surgery Unit, Istituto Nazionale per lo Studio e la Cura dei Tumori "Fondazione G. Pascale"IRCCS, Naples, Italy pattern was compared with contrast-enhanced computed tomography (CT) pattern.

Results There was a significant association between CEUS and CT pattern $\left(X^{2}=79.0 ; p<0.0001\right)$. A significant association was found between CEUS pattern and Ki-67 index $\left(X^{2}=24.6 ; p<0.0001\right)$. The hypervascular homogeneous CEUS typical pattern was associated with low tumor grading (G1 or G2) $\left(X^{2}=24.0 ; p<0.0001\right)$. CEUS pattern changed from hypervascular homogeneous in baseline to hypovascular/hypervascular inhomogeneous after SSA therapy, with a significant association between tumor response at CT scan and appearance of hypervascular inhomogeneous pattern at CEUS evaluation (6 months: $X^{2}=57.0 ; p<0.0001 ; 12$ months: $\left.X^{2}=49.8 ; p<0.0001\right)$. Conclusions In patients with P-NET, CEUS pattern correlates with tumor grading, being homogeneous in $\mathrm{G} 1-\mathrm{G} 2$ but not in G3 tumors. After therapy with SSAs, CEUS is predictive of response to SSAs. These findings seem to support a role of CEUS as prognostic and predictive factor of response.

Keywords CEUS · Prognosis · Prediction of response · Somatostatin analogues $\cdot$ Neuroendocrine tumors

\section{Introduction}

The incidence of pancreatic neuroendocrine tumors (P-NETs) is 1.8 in females and 2.6 in males per 1,000,000 per year. The majority of P-NETs are well differentiated G1 and G2, while G3 ones are uncommon [1-3]. One of the major prognostic factors affecting survival in P-NET patients is the presence of liver metastases, which occur in $24-31 \%$ of cases. Patients with P-NETs and liver metastases show a 5-year survival rate of $30-60 \%[4,5]$. 
Furthermore, large neoplasms are associated with worse outcomes; while small tumors do not seem to have an invariable benign behavior [6]. Besides many conventional and functional imaging tools used for diagnosis, tumor localization, tumor staging and evaluation of prognosis, contrast-enhanced ultrasound (CEUS) can play a significant role in the prognosis and follow-up of these tumors, not only for its high feasibility and reproducibility but also for its informative potential [7]. The combination of contrast agents with the ultrasound sonography (US) has made CEUS a perfusion technique, which provides information on tumor vascularity. CEUS is very useful for characterizing neuroendocrine tumors (NETs) within the pancreas and liver, due to the well-known high vascularity of these lesions. As known, the use of triphasic multislice computed tomography (CT) has revealed that most of pancreatic ductal adenocarcinomas present a hypovascular structure, while P-NETs are generally hypervascular [8]. In the field of pancreatic and liver lesions, CEUS facilitates an early diagnosis, through improved definition of the margins of the lesions, as well as a better differential diagnosis between tumor and non-tumor lesions and among different types of tumors [9-11]. CEUS has shown $82 \%$ of sensitivity for the diagnosis and characterization of liver lesions [12]. On this basis, CEUS has rapidly grown, and can now be used, not only to characterize pancreatic and liver lesions (malignant vs benign lesions); but also, to monitor functional response to therapy in patients with neoplastic lesions $[12,13]$. Monitoring tumor response to therapy is mandatory to tailor individual patient care and evaluate novel treatment choices $[14,15]$. In the therapeutic algorithm of NETs, somatostatin analogues (SSAs) are used both for anti-secretory and anti-proliferative effects. In non-functioning P-NETs, SSA therapy aims at the stabilization of tumor growth [16-18].

The aim of this study was to evaluate the prognostic role of CEUS, as well as to investigate the role of CEUS in predicting the effectiveness of therapy with SSAs in patients with P-NETs and liver metastases from P-NET.

\section{Patients and methods}

\section{Patients}

Between January 2010 and February 2013, 47 consecutive patients ( 25 males and 22 females; mean age 50 years old; range $26-76$ years old) with P-NET, admitted to the Unit of Neuroendocrine Tumors of the Department of Clinical Medicine and Surgery, University "Federico II" of Naples, underwent CEUS. The pathological diagnosis of P-NET was obtained by pancreatectomy (15 patients, $31.9 \%$ ), liver biopsy (22 patients, $46.8 \%$ ) and/
Table 1 Baseline patient characteristics

\begin{tabular}{ll}
\hline & P-NET $(n=47), n(\%)$ \\
\hline Age [median; (range)] & $50(26-76)$ \\
Sex & \\
M & $25(53.2)$ \\
F & $22(46.8)$ \\
Grading & \\
G1 & $11(23.4)$ \\
G2 & $26(55.3)$ \\
G3 & $10(21.3)$ \\
Tumor biology & \\
Sporadic & $36(76.6)$ \\
Familial & $11(23.4)$ \\
Histology & \\
Pancreatectomy & $15(31.9)$ \\
Liver biopsy & $22(46.8)$ \\
EUS-guided FNC (pancreas/liver) & $10(21.3)$ \\
Number of lesions & \\
Pancreas & $43(43.4)$ \\
Liver & $56(56.6)$ \\
Lesion size (mm; mean \pm SD) & $12.7 \pm 11.6$ \\
Pancreas & $25.5 \pm 16.0$ \\
Liver & $148.6(17.2-15,000)$ \\
Chromogranin A [ng/ml; median; (range)] & \\
SSA treatment & \\
\hline
\end{tabular}

$P$-NET pancreatic neuroendocrine tumor, EUS endoscopic ultrasound, $F N C$ fine needle cytology, SSA somatostatin analogue

or cell block cytology (EUS-guided FNC) (10 patients, $21.3 \%$ ). Eleven of 47 patients with P-NET were G1 (23.4\%), 26 G2 (55.3\%), 10 G3 (21.3\%). Eleven patients (5 males and 6 females) had a NET in the context of a multiple endocrine neoplasia type 1 syndrome (MEN 1), the remaining 36 patients were affected with a sporadic tumor. At the time of the study, the P-NET population included: 13 patients $(27.7 \%)$ with pancreatic lesions only, 8 patients $(17.0 \%)$ with liver lesions only, and 26 patients $(55.3 \%)$ with both pancreatic and liver lesions. A total of 99 NET lesions were considered, including 43 pancreatic and 56 liver lesions (Table 1). The thirty-seven G1-G2 P-NETs were treated with SSAs (octreotide LAR $30 \mathrm{mg}$ every 28 days, lanreotide autogel $120 \mathrm{mg}$ every 28 days). Sixteen out of the 37 patients were switched to high dose SSAs because of uncontrolled symptoms and/ or radiological progression. All G3 patients were treated with conventional systemic chemotherapy with cisplatin and etoposide as first choice.

All procedures performed in studies involving human participants were in accordance with the ethical standards of the institutional and/or national research committee and with the 1964 Helsinki Declaration and its later 
amendments or comparable ethical standards. For this type of study formal consent is not required.

\section{Methods}

CEUS was performed by the same physician with over 30 years (A.G.) and 15 years (A.D.S.) of experience, respectively. Examinations were performed using Prosound 10 Premier equipment (Aloka, Tokyo, Japan) or Aplio XG equipment (Toshiba, Tokyo, Japan) with $3.0-6.0 \mathrm{MHz}$ convex array broadband probes, and software for contrast media. Scans were performed with simultaneous dual imaging (gray-scale and contrast specific imaging). Imaging was B mode and continuous, and frame rate was 13/s. A contrast medium was injected into the blood stream $(2.4 \mathrm{ml})$ during the US examination of the upper abdomen. The US contrast media SonoVue ${ }^{\circledR}$ (Bracco, Milan, Italy) consists of microbubbles of sulfur hexafluoride in a shell phospholipid that is stable and resistant to pressure. This contrast agent offers many advantages, such as its ability to stay confined to vessels without diffuse into extravascular space because of its isotonic to plasma, which allow study only of tumor microcirculation in real time for several minutes [8, 19]. Most P-NETs, as well as their liver metastases, are highly vascularized with a dense intratumoral vascular network. As a result, they show the hypervascular homogeneous (typical pattern) pattern in the arterial phase characterized by early contrast enhancement only within the tumor mass. Only a small percentage of P-NETs show hypervascular inhomogeneous or hypovascular inhomogeneous pattern (atypical pattern) in the arterial phase that is characterized by a poor contrast enhancement within the tumor mass in the arterial phase. The evaluation of enhancement pattern was performed dynamically during all phases of the examination and was compared with the normal parenchyma and with the echogenicity of the lesion before administration of the US contrast agent. As previously reported by Malagò et al. CEUS patterns were compared to the histologic reports to evaluate the correlation with $\mathrm{Ki}-67$ index in tumor samples [20].

On the basis of CEUS enhancement pattern, tumor lesions were classified as hypervascular homogeneous (without hypo-enhancing or non-enhancing areas within the tumor lesion) and inhomogeneous (one or more hypoenhancing or non-enhancing areas within the tumor lesion) in the arterial phase $[20,21]$. In all patients, CEUS was performed at baseline, 3, 6 and 12 months after the beginning of SSAs, and the results were compared with the density pattern of multi-slice CT performed at baseline, 6 and 12 months after treatment. Radiological response was evaluated by CT according to the Response Evaluation Criteria in Solid Tumors (RECIST criteria version 1.1), by considering the sum of the longest diameter of target pancreatic or liver lesions with the longest diameter of at least $10 \mathrm{~mm}$ [22]. Triphasic multi-slice CT scan was performed in all subjects with a multi-detector row equipment (Aquilion 64, Toshiba, Japan) using a detector configuration of $1 \mathrm{~mm} \times 32 \mathrm{~mm}$, a table feed of $36 \mathrm{~mm} / \mathrm{s}$ and a gantry rotation time of 0.75 (pitch factor $=0.844$ ), $3 \mathrm{~mm}$ slice thickness, $120 \mathrm{kVp}$ and automatic dose modulation (Noise Index $=12.5$ ) [23-25]. Contrast-enhanced CT was performed with arterial, pancreatic and portal venous phase, and acquisitions were performed with fix scan delays of 35,55 and $80 \mathrm{~s}$ after i.v. bolus injection $(3 \mathrm{ml} / \mathrm{s})$ of $100 \mathrm{ml}$ of non-ionic iodinated contrast media (Ultravist 370; Bayer, Berlin, Germany) followed by $200 \mathrm{ml}$ of saline solution with a dual-head injector (Stellant Injection System, Medrad Inc., United States) and further hydration with 1.801 of $0.9 \% \mathrm{NaCl}$ solution in case of diabetic nephropathy [26, 27]. Histology, performed according to the 2010 WHO classifications of NETs, was the gold standard for the diagnostic study [2]. The Ki-67 index was evaluated in all cases using MIB-1 antibodies as a percentage of 500 2000 tumor cells counted in areas of strongest nuclear labeling ("hot spots") [2].

\section{Statistical analysis}

Statistical analysis was performed with the SPSS statistical program version 20 for Windows (SPSS, Inc., Chicago, IL, USA). Descriptive analyses were performed using mean, median and/or standard deviation (SD) for quantitative variables. Comparison between numerical data were performed using linear regression. The comparison between the categorical data were performed by the Chi-square test with the Yates correction or Fisher exact test as appropriate. Data are expressed as mean \pm SD. $p$ values are given for these analyses. The significance was set at $5 \%$.

\section{Results}

\section{Prognostic study}

Before therapy, all pancreatic and liver lesions from patients with P-NET were characterized by a hypervascular CEUS pattern in the early arterial phase (Fig. 1). In particular, before treatment CEUS pattern was hypervascular homogeneous in $39(90.7 \%)$ and inhomogeneous in $4(9.3 \%)$ pancreatic lesions, while it was homogeneous in $47(83.9 \%)$ and inhomogeneous in $9(16.1 \%)$ liver lesions. There was no association between CEUS pattern and size of the lesions $\left(R^{2}=0.005, p>0.05\right)$. A significant association was found between CEUS pattern and $\mathrm{Ki}-67$ index $\left(X^{2}=24.6 ; p<0.0001\right)$. The hypervascular homogeneous 
Fig. 1 a Conventional ultrasound sonography (US) and $\mathbf{b}$ hypervascular homogeneous contrast-enhanced ultrasound (CEUS) pattern in a liver metastasis (arrows) from a patient with pancreatic neuroendocrine tumor (P-NET); c conventional US and $\mathbf{d}$ hypervascular inhomogeneous CEUS pattern in a liver metastasis (arrows) from a patient with P-NET
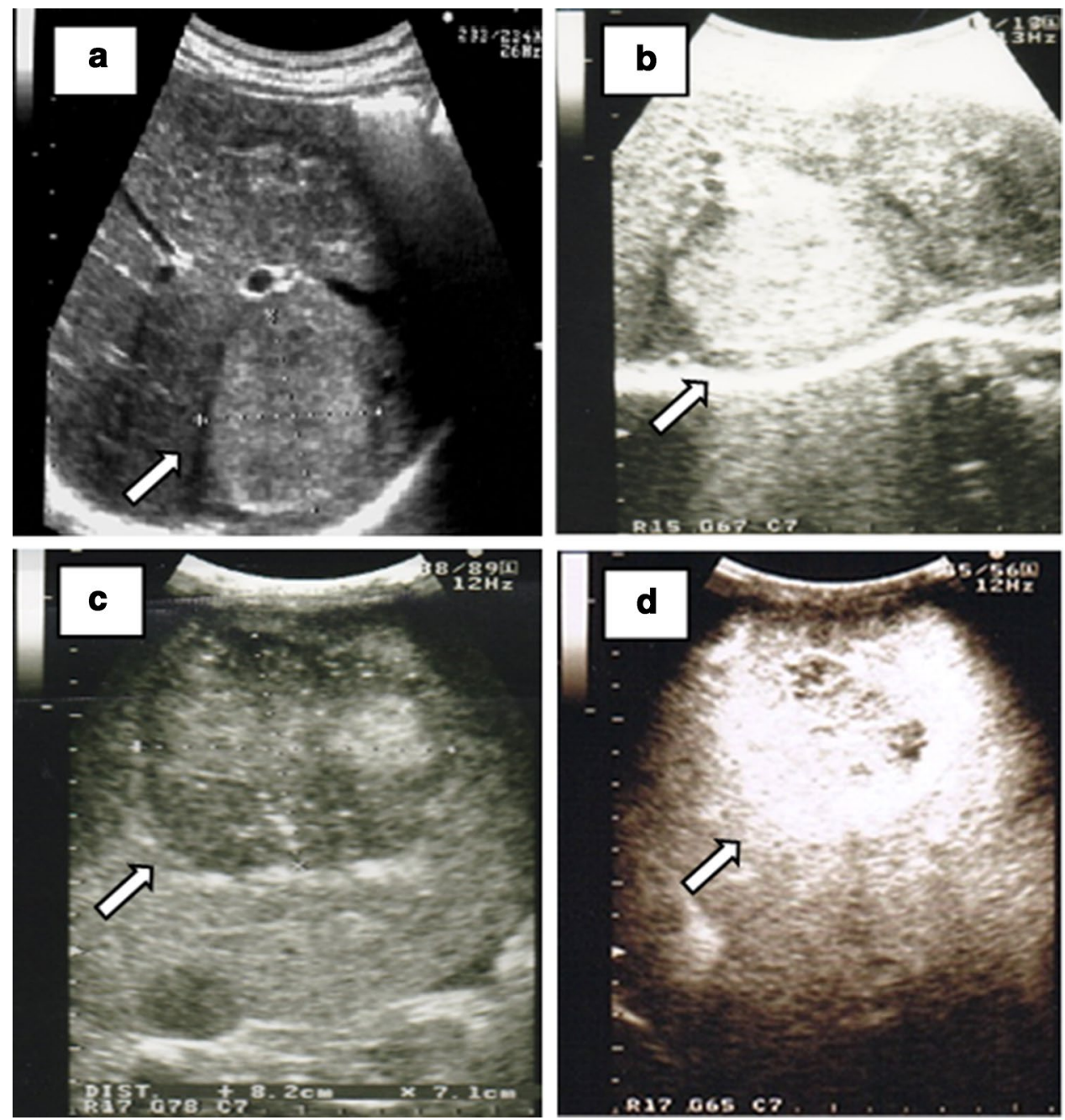

CEUS pattern was associated with low tumor grading $\left(X^{2}=24.0 ; p<0.0001\right)$.

\section{Predictive study}

At baseline there was a significant association between CEUS and contrast-enhanced CT pattern $\left(X^{2}=79.0\right.$; $p<0.0001)$. In particular, the absence of necrosis observed at CT scans corresponded to hypervascular homogeneous CEUS pattern. At 12-month follow-up, 32 of 37 patients (86.5) were evaluable for radiological response according to RECIST 1.1 criteria. After therapy with SSAs, 28 of 32 patients $(87.5 \%)$ were stable, while 4 patients $(12.5 \%)$ were in progression at 12-month follow-up at CT scan. Patients with radiological progression were switched to other targeted therapies.

CEUS and CT pattern variations after biotherapy are reported in Table 2. At 3-month follow-up, CEUS was performed in 47 tumor lesions of 12 patients. As compared to baseline, a hypervascular homogeneous CEUS pattern in the arterial phase was unchanged in $12(54.5 \%)$ pancreatic and in $15(60 \%)$ liver lesions, while a hypervascular inhomogeneous CEUS pattern appeared in 10 (45.5\%) pancreatic and in 10 (40\%) liver lesions, respectively (Fig. 2).

At 6- and 12-month follow-ups, there was a significant association between tumor characteristics at CT (necrosis) and the appearance of hypervascular inhomogeneous CEUS pattern at the early arterial phase (6 months: $X^{2}=57.0 ; p<0.0001 ; 12$ months: $\left.X^{2}=49.8 ; p<0.0001\right)$. By comparing the 3-month CEUS pattern with 6- and 12-month CT evaluation, the appearance of an inhomogeneous CEUS pattern was significantly associated to tumor pattern at CT (6 months: $X^{2}=14.8 ; p<0.0001 ; 12$ months: $\left.X^{2}=5.0 ; p=0.04\right)$.

\section{Discussions}

CEUS is a valid non-invasive and accurate imaging modality for quantifying tumor vascularity. As compared to 
Table 2 CEUS and CT pattern of pancreatic and liver lesions 3-, 6- and 12-month follow-up after biotherapy

\begin{tabular}{|c|c|c|c|c|c|c|}
\hline & \multicolumn{3}{|c|}{ Hypervascular CEUS pattern, $n(\%)^{\mathrm{a}}$} & \multicolumn{3}{|l|}{ CT pattern, $n(\%)$} \\
\hline & $\begin{array}{l}\text { Persistent } \\
\text { homogeneous }\end{array}$ & $\begin{array}{l}\text { Persistent } \\
\text { inhomogeneous }\end{array}$ & $\begin{array}{l}\text { Appearance of } \\
\text { inhomogeneous }^{b}\end{array}$ & $\begin{array}{l}\text { Persistent absence } \\
\text { of necrosis }\end{array}$ & $\begin{array}{l}\text { Persistent presence } \\
\text { of necrosis }\end{array}$ & $\begin{array}{l}\text { Appearance } \\
\text { of necrosis }\end{array}$ \\
\hline \multicolumn{7}{|l|}{ Liver } \\
\hline 3 months & $15 / 25(60.0)$ & $0 / 25(0.0)$ & $10 / 25(40.0)$ & - & - & - \\
\hline 6 months & $17 / 43(39.5)$ & $4 / 43(9.3)$ & $22 / 43(51.2)$ & $17 / 44(38.7)$ & 6/44 (13.6) & $21 / 44(47.7)$ \\
\hline 12 months & $14 / 40(35.0)$ & $2 / 40(5.0)$ & $24 / 40(60.0)$ & $4 / 30(13.3)$ & $2 / 30(6.7)$ & $24 / 30(80.0)$ \\
\hline \multicolumn{7}{|l|}{ Pancreas } \\
\hline 3 months & $10 / 22(45.5)$ & $2 / 22(9.0)$ & $10 / 22(45.5)$ & - & - & - \\
\hline 6 months & $12 / 33(36.4)$ & $3 / 33(9.1)$ & $18 / 33(54.5)$ & $11 / 22(50.0)$ & $1 / 22(4.5)$ & $10 / 22(45.5)$ \\
\hline 12 months & 9/31 (29.0) & 2/31 (6.5) & $20 / 31(64.5)$ & $11 / 32(34.4)$ & $2 / 32(6.3)$ & $19 / 32(59.3)$ \\
\hline
\end{tabular}

$P$-NET pancreatic neuroendocrine tumor, CEUS contrast-enhanced ultrasound, $C T$ computed tomography

${ }^{a}$ Related to the early arterial phase

b Hypovascular or hypervascular

Fig. 2 Persistence of hypervascular inhomogeneous CEUS pattern in a liver metastasis (arrows) after treatment with somatostatin analogues (SSA) $s$ at baseline (a) and at 3- (b), 6(c) and 12-month (d) follow up
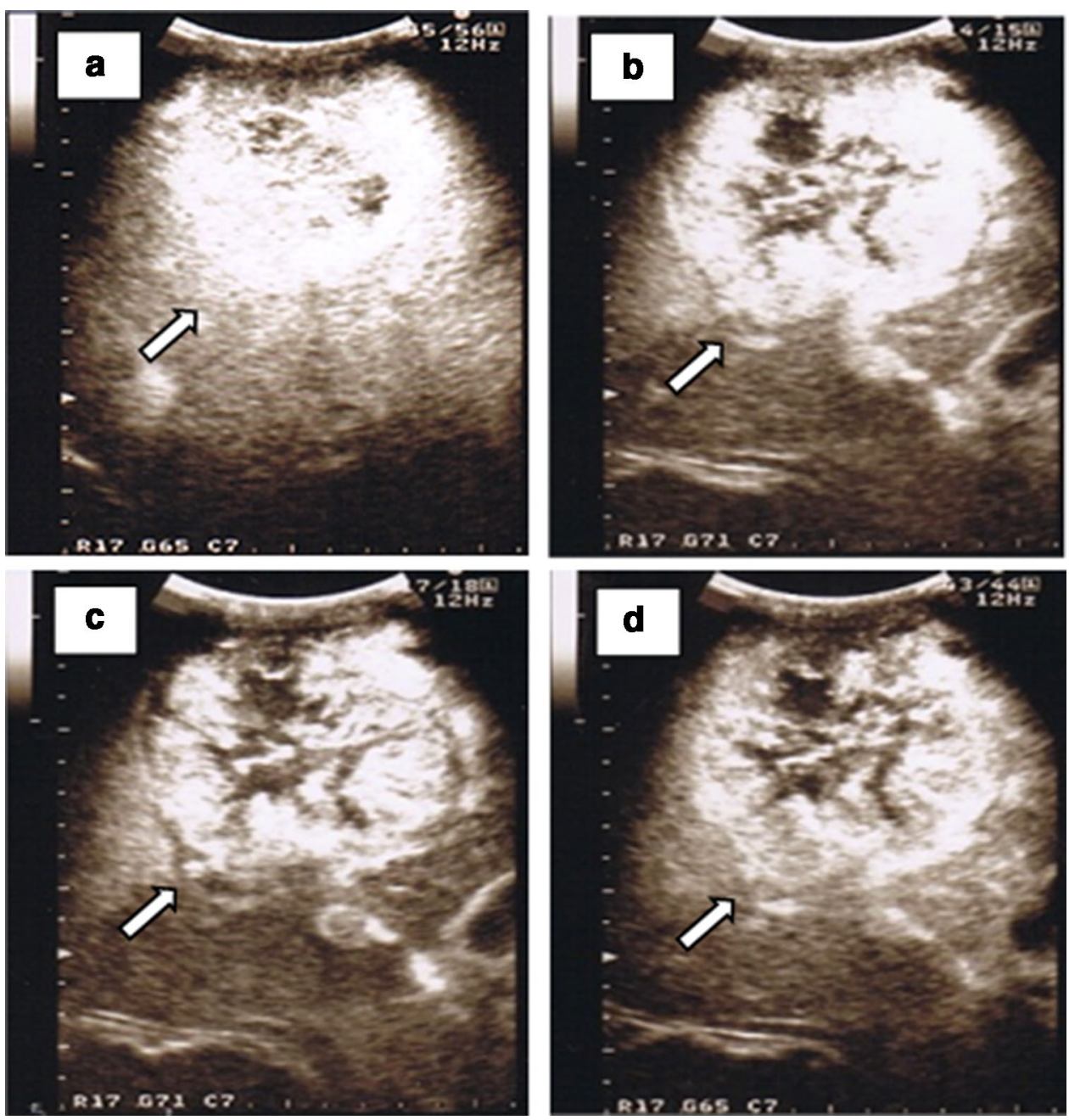

contrast-enhanced CT and MRI, CEUS may be complementary in the characterization of tumor lesions, providing specific information about vascularity [28, 29].
P-NETs are richly vascularized tumors. They represent, therefore, optimal candidates for CEUS application. Characterization of tumor microcirculation is helpful to obtain 
a differential diagnosis among different histotypes. Liver metastases of NETs have the same characteristics of hypervascularity of the primary lesion and the same CEUS pattern on the arterial phase [30]. At present, there are few data on the usefulness of CEUS in the evaluation of the prognostic role in patients with liver metastases from NET and no information specifically for P-NET patients [31]. CEUS could detect the typical hypervascular homogeneous pattern of NETs and those differences in imaging features may depend on primary lesion, size, proliferation marker, and extent of the degenerative changes [31]. Furthermore, preclinical data on mice has already shown the possibility of early identification of tumor angiogenesis and monitoring biological therapy using microbubbles of contrast medium [32]. In the current retrospective study, a significant association was found between CEUS and CT pattern, suggesting that CEUS has a predictive role on tumor response for lesions well defined at US.

Contrast-enhanced CT correlates with the pathological tumor grade in NETs and represents an adequate tool to characterize and monitor NET lesions [33]. However, the ability of CEUS in defining the characteristics of NET lesions and monitoring changes after therapy could reduce the need for frequent CT scans (time and interval of execution), thereby reducing the exposure of patients to radiation. The positive association, we found, between CEUS pattern and Ki-67 index explains the hypervascular homogeneous pattern in tumor lesions with low proliferation activity. On the contrary, tumor lesions with an inhomogeneous CEUS pattern (hypervascular or hypovascular) before therapy were found to be characterized by high proliferation activity [20]. In practice, CEUS pattern is able to predict tumor aggressiveness. In this meaning, its usefulness is to perform a per lesion analysis by predicting the proliferative activity, and of consequence, the growth rate, of all US evaluable lesions.

At the same time, CEUS seems to be a reliable predictor of tumor response. The ability to predict tumor response to antiangiogenic therapy has been previously recognized in advanced hepatocellular carcinomas [15, 34, 35]. In the current study, CEUS was able to identify those tumor lesions potentially responsive to specific therapies such as SSAs, helping to select the best treatment option.

CEUS could play an important role in the follow-up of patients with metastatic P-NETs treated with SSAs and could be of benefit in monitoring the response to these therapies at intervals between several CTs [36, 37]. In the current study, a relationship between CEUS pattern variations and tumor response to SSAs at CT evaluation was observed. In detail, the appearance of a hypervascular inhomogeneous CEUS pattern at 6- and 12-month after SSA therapy was a marker of tumor response, corresponding to radiological stability and appearance of necrosis at CT scan. The development of necrosis after therapies in lesions without necrosis at baseline can indicate tumor cell death. This is considered as response to the treatment. In this study, CEUS and contrast-enhanced multi-slice CT pattern were considerably concordant. At 6- and 12-month followups after therapy, a hypervascular inhomogeneous CEUS pattern was found in 52.6 and $62.0 \%$ of all pancreatic and liver lesions. Similarly, necrosis appeared at multi-slice CT in 47.0 and $69.3 \%$ of all considered lesions, without evidence of tumor progression. In other words, appearance of either an inhomogeneous CEUS pattern or CT appearance of necrosis is a reliable indicator of response to therapy with SSAs, regardless of size. Interestingly, an early indication of response to SSAs was obtained by performing CEUS 3 months after therapy, both at pancreatic and liver level. This finding suggests that CEUS can be used early in the follow-up of patients with NET under treatment with SSAs, to predict tumor outcome and decide if therapy has to be maintained or stopped because ineffective.

In summary, CEUS pattern could help diagnosis, prognostic definition and follow-up of pancreatic and liver lesions from P-NET, also limiting the exposure of patients to radiation and potentially harmful contrast media and invasive methods. CEUS has also shown in this study to be promising in the assessment of response to SSAs. In fact, differences in CEUS pattern before and after this therapy are quite evident and reproducible between responders and non-responders. CEUS could recognize non-responding patients early to propose alternative therapies to these patients. In particular, CEUS offers a tool to quickly test and frequently reassess the activity of P-NETs without subjecting the patient to psychological and physical stress as well as other invasive procedures. Further studies with prospective study design are required to definitely establish relevance and role of CEUS in NET diagnosis and follow-up.

Acknowledgements We are grateful for the authors' help in the collection, analysis and interpretation of data, in the writing and proofreading of the article and in the decision to submit the article for publication.

\section{Compliance with ethical standards}

Funding This research did not receive any specific grant from any funding agency in the public, commercial or not-for-profit sector.

Conflict of interest Authors declare that they have no conflict of interest.

Ethical approval All procedures performed in studies involving human participants were in accordance with the ethical standards of the institutional and/or national research committee and with the 1964 Helsinki Declaration and its later amendments or comparable ethical standards. 
Informed consent For this type of study formal consent is not required.

\section{References}

1. Fraenkel M, Kim M, Faggiano A, de Herder WW, Valk GD (2014) Incidence of gastroenteropancreatic neuroendocrine tumours: a systematic review of the literature. Endocr Relat Cancer 21(3):R153-R163. doi:10.1530/ERC-13-0125

2. Bosman FT, World Health Organization, International Agency for Research on Cancer (2010) WHO classification of tumours of the digestive system. World Health Organization classification of tumours, vol 3, 4th edn. International Agency for Research on Cancer, Lyon

3. Ferolla P, Faggiano A, Mansueto G, Avenia N, Cantelmi MG, Giovenali P, De Caro MLDB, Milone F, Scarpelli G, Masone S, Santeusanio F, Lombardi G, Angeletti G, Colao A (2008) The biological characterization of neuroendocrine tumors: the role of neuroendocrine markers. J Endocrinol Invest 31(3):277-286

4. Panzuto F, Nasoni S, Falconi M, Corleto VD, Capurso G, Cassetta S, Di Fonzo M, Tornatore V, Milione M, Angeletti S, Cattaruzza MS, Ziparo V, Bordi C, Pederzoli P, Delle Fave G (2005) Prognostic factors and survival in endocrine tumor patients: comparison between gastrointestinal and pancreatic localization. Endocr Relat Cancer 12(4):1083-1092. doi:10.1677/erc.1.01017

5. Pavel M, Baudin E, Couvelard A, Krenning E, Oberg K, Steinmuller T, Anlauf M, Wiedenmann B, Salazar R (2012) ENETS Consensus Guidelines for the management of patients with liver and other distant metastases from neuroendocrine neoplasms of foregut, midgut, hindgut, and unknown primary. Neuroendocrinology 95(2):157-176. doi:10.1159/000335597

6. Lombardi M, De Lio N, Funel N, Sardella C, Russo D, Urbani C, Rossi G, Campani D, Martino E, Marcocci C, Boggi U, Bogazzi F (2015) Prognostic factors for pancreatic neuroendocrine neoplasms (pNET) and the risk of small non-functioning pNET. J Endocrinol Invest 38(6):605-613. doi:10.1007/ s40618-014-0219-x

7. Claudon M, Dietrich CF, Choi BI, Cosgrove DO, Kudo M, Nolsoe CP, Piscaglia F, Wilson SR, Barr RG, Chammas MC, Chaubal NG, Chen MH, Clevert DA, Correas JM, Ding H, Forsberg F, Fowlkes JB, Gibson RN, Goldberg BB, Lassau N, Leen EL, Mattrey RF, Moriyasu F, Solbiati L, Weskott HP, Xu HX (2013) Guidelines and good clinical practice recommendations for Contrast Enhanced Ultrasound (CEUS) in the liver-update 2012: a WFUMB-EFSUMB initiative in cooperation with representatives of AFSUMB, AIUM, ASUM, FLAUS and ICUS. Ultrasound Med Biol 39(2):187-210. doi:10.1016/j.ultrasmedbio.2012.09.002

8. Oshikawa O, Tanaka S, Ioka T, Nakaizumi A, Hamada Y, Mitani $\mathrm{T}$ (2002) Dynamic sonography of pancreatic tumors: comparison with dynamic CT. Am J Roentgenol 178(5):1133-1137

9. Wu H, Lu Q, Luo Y, He XL, Zeng Y (2010) Application of contrast-enhanced intraoperative ultrasonography in the decisionmaking about hepatocellular carcinoma operation. World J Gastroenterol 16(4):508-512

10. Ren XL, Yan RL, Yu XH, Zheng Y, Liu JE, Hou XB, Zuo SY, Fu XY, Chang H, Lu JH (2010) Biliary cystadenocarcinoma diagnosed with real-time contrast-enhanced ultrasonography: report of a case with diagnostic features. World J Gastroenterol 16(1):131-135

11. D’Onofrio M, Zamboni G, Tognolini A, Malago R, Faccioli N, Frulloni L, Pozzi Mucelli R (2006) Mass-forming pancreatitis: value of contrast-enhanced ultrasonography. World J Gastroenterol 12(26):4181-4184
12. Sundin A, Arnold R, Baudin E, Cwikla JB, Eriksson B, Fanti S, Fazio N, Giammarile F, Hicks RJ, Kjaer A, Krenning E, Kwekkeboom D, Lombard-Bohas C, O'Connor JM, O'Toole D, Rockall A, Wiedenmann B, Valle JW, Vullierme MP, All other Antibes Consensus Conference p (2017) ENETS consensus guidelines for the standards of care in neuroendocrine tumors: radiological, nuclear medicine and hybrid imaging. Neuroendocrinology. doi: $10.1159 / 000471879$

13. Morin SH, Lim AK, Cobbold JF, Taylor-Robinson SD (2007) Use of second generation contrast-enhanced ultrasound in the assessment of focal liver lesions. World $\mathrm{J}$ Gastroenterol 13(45):5963-5970

14. Piscaglia F, Corradi F, Mancini M, Giangregorio F, Tamberi S, Ugolini G, Cola B, Bazzocchi A, Righini R, Pini P, Fornari F, Bolondi L (2007) Real time contrast enhanced ultrasonography in detection of liver metastases from gastrointestinal cancer. BMC Cancer 7:171. doi:10.1186/1471-2407-7-171

15. Massironi S, Conte D, Sciola V, Pirola L, Paggi S, Fraquelli M, Ciafardini C, Spampatti MP, Peracchi M (2010) Contrastenhanced ultrasonography in evaluating hepatic metastases from neuroendocrine tumours. Dig Liver Dis 42(9):635-641. doi:10.1016/j.dld.2010.01.009

16. Oberg K, Kvols L, Caplin M, Delle Fave G, de Herder W, Rindi G, Ruszniewski P, Woltering EA, Wiedenmann B (2004) Consensus report on the use of somatostatin analogs for the management of neuroendocrine tumors of the gastroenteropancreatic system. Ann Oncol 15(6):966-973

17. Asnacios A, Courbon F, Rochaix P, Bauvin E, Cances-Lauwers V, Susini C, Schulz S, Boneu A, Guimbaud R, Buscail L (2008) Indium-111-pentetreotide scintigraphy and somatostatin receptor subtype 2 expression: new prognostic factors for malignant welldifferentiated endocrine tumors. J Clin Oncol 26(6):963-970. doi:10.1200/JCO.2007.12.7431

18. Srirajaskanthan R, Kayani I, Quigley AM, Soh J, Caplin ME, Bomanji J (2010) The role of 68 Ga-DOTATATE PET in patients with neuroendocrine tumors and negative or equivocal findings on 111In-DTPA-octreotide scintigraphy. J Nucl Med 51(6):875882. doi:10.2967/jnumed.109.066134

19. Seicean A, Badea R, Stan-Iuga R, Gulei I, Pop T, Pascu O (2010) The added value of real-time harmonics contrast-enhanced endoscopic ultrasonography for the characterisation of pancreatic diseases in routine practice. J Gastrointestin Liver Dis 19(1):99-104

20. Malago R, D’Onofrio M, Zamboni GA, Faccioli N, Falconi M, Boninsegna L, Mucelli RP (2009) Contrast-enhanced sonography of nonfunctioning pancreatic neuroendocrine tumors. Am J Roentgenol 192(2):424-430. doi:10.2214/AJR.07.4043

21. D’Onofrio M, Barbi E, Dietrich CF, Kitano M, Numata K, Sofuni A, Principe F, Gallotti A, Zamboni GA, Mucelli RP (2012) Pancreatic multicenter ultrasound study (PAMUS). Eur J Radiol 81(4):630-638. doi:10.1016/j.ejrad.2011.01.053

22. Eisenhauer EA, Therasse P, Bogaerts J, Schwartz LH, Sargent D, Ford R, Dancey J, Arbuck S, Gwyther S, Mooney M, Rubinstein L, Shankar L, Dodd L, Kaplan R, Lacombe D, Verweij J (2009) New response evaluation criteria in solid tumours: revised RECIST guideline (version 1.1). Eur J Cancer 45(2):228-247. doi:10.1016/j.ejca.2008.10.026

23. Aspestrand F, Kolmannskog F, Jacobsen M (1993) CT, MR imaging and angiography in pancreatic apudomas. Acta Radiol 34(5):468-473

24. de Herder WW, Niederle B, Scoazec JY, Pauwels S, Kloppel G, Falconi M, Kwekkeboom DJ, Oberg K, Eriksson B, Wiedenmann B, Rindi G, O'Toole D, Ferone D (2006) Well-differentiated pancreatic tumor/carcinoma: insulinoma. Neuroendocrinology 84(3):183-188. doi:10.1159/000098010

25. Sundin A, Vullierme MP, Kaltsas G, Plockinger U (2009) ENETS consensus guidelines for the standards of care in 
neuroendocrine tumors: radiological examinations. Neuroendocrinology 90(2):167-183. doi:10.1159/000184855

26. Camera L, Severino R, Faggiano A, Masone S, Mansueto G, Maurea S, Fonti R, Salvatore M (2014) Contrast enhanced multidetector CT and MR findings of a well-differentiated pancreatic vipoma. World J Radiol 6(10):840-845. doi:10.4329/wjr. v6.i10.840

27. Stacul F, van der Molen AJ, Reimer P, Webb JA, Thomsen HS, Morcos SK, Almen T, Aspelin P, Bellin MF, Clement O, Heinz-Peer G (2011) Contrast induced nephropathy: updated ESUR contrast media safety committee guidelines. Eur Radiol 21(12):2527-2541. doi:10.1007/s00330-011-2225-0

28. Steinmuller T, Kianmanesh R, Falconi M, Scarpa A, Taal B, Kwekkeboom DJ, Lopes JM, Perren A, Nikou G, Yao J, Delle Fave GF, O'Toole D (2008) Consensus guidelines for the management of patients with liver metastases from digestive (neuro) endocrine tumors: foregut, midgut, hindgut, and unknown primary. Neuroendocrinology 87(1):47-62. doi:10.1159/000111037

29. Li R, Tang CL, Yang D, Zhang XH, Cai P, Ma KS, Guo DY, Ding SY (2016) Primary hepatic neuroendocrine tumors: clinical characteristics and imaging features on contrast-enhanced ultrasound and computed tomography. Abdom Radiol (NY). doi:10.1007/ s00261-016-0770-3

30. Mork H, Ignee A, Schuessler G, Ott M, Dietrich CF (2007) Analysis of neuroendocrine tumour metastases in the liver using contrast enhanced ultrasonography. Scand J Gastroenterol 42(5):652-662. doi:10.1080/00365520601021765

31. Dorffel Y, Wermke W (2008) Neuroendocrine tumors: characterization with contrast-enhanced ultrasonography. Ultraschall Med 29(5):506-514. doi:10.1055/s-2008-1027555
32. Pysz MA, Foygel K, Panje CM, Needles A, Tian L, Willmann JK (2011) Assessment and monitoring tumor vascularity with contrast-enhanced ultrasound maximum intensity persistence imaging. Invest Radiol 46(3):187-195. doi:10.1097/ RLI.0b013e3181f9202d

33. Takumi K, Fukukura Y, Higashi M, Ideue J, Umanodan T, Hakamada H, Kanetsuki I, Yoshiura T (2015) Pancreatic neuroendocrine tumors: correlation between the contrast-enhanced computed tomography features and the pathological tumor grade. Eur J Radiol 84(8):1436-1443. doi:10.1016/j.ejrad.2015.05.005

34. Zocco MA, Garcovich M, Lupascu A, Di Stasio E, Roccarina D, Annicchiarico BE, Riccardi L, Ainora ME, Ponziani F, Caracciolo G, Rapaccini GL, Landolfi R, Siciliano M, Pompili M, Gasbarrini A (2013) Early prediction of response to sorafenib in patients with advanced hepatocellular carcinoma: the role of dynamic contrast enhanced ultrasound. J Hepatol 59(5):10141021. doi:10.1016/j.jhep.2013.06.011

35. Roccarina D, Garcovich M, Ainora ME, Riccardi L, Pompili M, Gasbarrini A, Zocco MA (2015) Usefulness of contrast enhanced ultrasound in monitoring therapeutic response after hepatocellular carcinoma treatment. World J Hepatol 7(14):1866-1874. doi:10.4254/wjh.v7.i14.1866

36. Figueiras RG, Padhani AR, Goh VJ, Vilanova JC, Gonzalez SB, Martin CV, Caamano AG, Naveira AB, Choyke PL (2011) Novel oncologic drugs: what they do and how they affect images. Radiographics 31(7):2059-2091. doi:10.1148/rg.317115108

37. Kiessling F (2010) Science to practice: the dawn of molecular US imaging for clinical cancer imaging. Radiology 256(2):331333. doi:10.1148/radiol. 100717 